\title{
Massive rotator cuff tears: functional outcome after debridement or arthroscopic partial repair
}

\author{
Alexander Berth • Wolfram Neumann • \\ Friedemann Awiszus • Géza Pap
}

Received: 7 January 2010/ Accepted: 27 January 2010/Published online: 3 March 2010

(C) Springer-Verlag 2010

\begin{abstract}
Background The surgical treatment of massive rotator cuff tears (RCT) is still controversial and can be based on a variety of different surgical repair methods. This study investigated the effectiveness of arthroscopic debridement or arthroscopic partial repair in patients with massive RCT. Materials and methods This prospective, randomized study involved forty-two patients with massive RCT (fatty infiltration stage 3 or 4) treated with either arthroscopic partial repair or arthroscopic debridement were selected to detect possible differences in functional outcome. Both groups were matched according to age and gender. Patients were examined before, and $16 \pm 3$ and $24 \pm 2$ months after surgery. The status of the rotator cuff repair was determined using ultrasonographic evaluation.

Results Regardless of the treatment group, postoperative results demonstrated highly significant improvements compared with preoperative values in most parameters. The overall Constant score in the partial repair group was superior to the outcome in the debridement group $(P<0.01$, $F=8.561)$, according to better results in abduction $(P<0.01, F=13.249)$, activity $(P<0.01, F=21.391)$ and motion $(P<0.01, F=4.967)$. All treatment groups
\end{abstract}

A. Berth · W. Neumann · F. Awiszus

Department of Orthopaedics, Otto-von-Guericke-University, 39120 Magdeburg, Germany

G. Pap

Centre of Orthopaedics and Traumatology, Park-Hospital

Leipzig, 04289 Leipzig, Germany

A. Berth $(\bowtie)$

Orthopädische Universitätsklinik, Universitätsklinikum A. ö. R.,

Leipziger Str. 44, 39120 Magdeburg, Germany

e-mail: alexander.berth@med.ovgu.de had similar pain relief $(P=0.172, F=1.802)$ and satisfaction, reflected in equal values of disabilities of the arm, shoulder and hand (DASH) score $(P=0.948, F=0.004)$. Ultrasonography revealed structural failure of the partial rotator cuff repair in 52\% at final follow-up.

Conclusions During the follow-up period all patients in our series had good or satisfactory outcome after rotator cuff surgery. Regardless of high rates of structural failure of the partial rotator cuff repair, the results of arthroscopic partial rotator cuff repair demonstrated slightly better functional outcome than debridement.

Keywords Shoulder - Rotator cuff tear .

Arthroscopic repair

\section{Introduction}

Lesions of the rotator cuff are a common source of pain, impairment and disability of the shoulder, especially in people aged 60 years and older [1,2]. The current management of patients with rotator cuff tears (RCT) includes a wide range of non-pharmacological [3], pharmacological [4] and surgical modalities [5] and depends on the location, size and genesis of the lesion [6-9]. Operative repair of small and medium-sized RCT consistently yields good and satisfactory outcome in a high percentage of patients [10]. In contrast, surgical treatment of large or massive RCT can be technically difficult due to tendon retraction, muscle atrophy and fatty degeneration. In these cases, the results of rotator cuff repair are more inhomogeneous, and clinical outcome is considered to be correlated with size of tendon lesion and stage of fatty muscle degeneration [11, 12]. In particular, re-rupture after rotator cuff repair is known to occur in $20-65 \%$ over time $[13,14]$. In massive, contracted 
RCT, arthroscopic debridement or partial repair of the remaining rotator cuff tendons are two surgical treatment options. Although inferior to the results of complete rotator cuff repair, both methods also lead to significant improvements of shoulder function [15-17].

A limited number of studies are available focussing on comparison of functional outcome following arthroscopic debridement or partial repair in patients with massive RCT, and results are inconsistent [17-20]. Furthermore, partial rotator cuff repair in these studies was done in a traditional open or mini-open technique, raising the question of whether the rapid improvement in arthroscopic rotator cuff repair techniques can also have a positive effect on the clinical results of arthroscopic partial repair for massive irreparable RCT.

Therefore, the purpose of our matched-pair study is to clarify the effectiveness of arthroscopic debridement or arthroscopic partial repair in patients with massive RCT. These clinical aspects might be of particular interest in respect to the different invasiveness and rehabilitation period of these two treatment options.

\section{Materials and methods}

\section{Patients}

The present prospective study involved 42 patients with symptomatic unilateral full-thickness RCT who were surgically treated at our institution from May 2006 to May 2007. The patients in this study were divided into two groups: group 1 (arthroscopic partial rotator cuff repair) and group 2 (arthroscopic debridement, subacromial decompression). Both groups were matched according to age, gender and follow-up. The descriptive data of the patient groups are summarized in Table 1.

None of these patients reported discomfort in the shoulder of the uninvolved side. The non-affected shoulder was examined clinically and showed no signs of RCT. Additionally, ultrasound investigation showed moderate signs of tendon degeneration but no full-thickness RCT. Antero-posterior, axial and scapular view radiographs of the affected side were performed to exclude considerable osteoarthritis of the shoulder. All patients had symptoms for longer than 12 months before surgery and underwent a course of conservative treatment including anti-inflammatory medication and home-based physical therapy. The indication for operative treatment was persistent, severe or moderate pain at rest and loss of shoulder function despite conservative treatment. No other significant neuromuscular or skeletal pathologies were present.

The assessment of a massive irreparable RCT which makes a complete anatomic repair not possible, was based
Table 1 Patient data according to treatment group

\begin{tabular}{llll}
\hline & $\begin{array}{l}\text { Group 1 } \\
\text { (partial repair) }\end{array}$ & $\begin{array}{l}\text { Group 2 } \\
\text { (debridement) }\end{array}$ & All \\
\hline Number of patients & 21 & 21 & 42 \\
Sex (male/female) & $15 / 6$ & $16 / 5$ & $31 / 11$ \\
Age (years) & $62.5 \pm 2.3$ & $64.3 \pm 3.4$ & $63.4 \pm 3.0$ \\
Minimum & 60 & 60 & 60 \\
Maximum & 67 & 72 & 72 \\
Follow-up 1 (months) & $16.2 \pm 2.8$ & $17.6 \pm 3.2$ & $16.8 \pm 3.0$ \\
Minimum & 12 & 13 & 12 \\
Maximum & 21 & 24 & 24 \\
Follow-up 2 (months) & $23.8 \pm 1.9$ & $24.7 \pm 19.9$ & $24.2 \pm 1.95$ \\
Minimum & 21 & 21 & 21 \\
Maximum & 28 & 28 & 28 \\
Side (right/left) & $14 / 7$ & $17 / 4$ & $31 / 11$ \\
Involvement of the & $71 \%$ & $66 \%$ & $69 \%$ \\
dominant arm & & & \\
\hline
\end{tabular}

Data are given as mean \pm standard deviation

on the evaluation of the tendon retraction and fatty degeneration by a preoperative magnetic resonance imaging (MRI) investigation (see below). Therefore, the decision to perform arthroscopic partial repair or debridement was based on an intensive preoperative interview. Patients were introduced to both surgical procedures with a description of their pros and cons. Under advice of limited prospect of success, we offered the patients the option of arthroscopic partial rotator cuff repair with requisite temporary immobilization (such as willingness to wear an abduction brace for 4 weeks postoperatively) and rehabilitation after surgery. As an alternative, the second treatment option of debridement and decompression alone with less limiting treatment after surgery was introduced.

The study was performed in accordance with the ethical standards of the 1964 Declaration of Helsinki and was approved by the local ethical committee. A written informed consent was obtained from all patients.

\section{Evaluation of rotator cuff tears}

Full RCT was diagnosed preoperatively by magnetic resonance imaging. On the basis of preoperative radiological findings, the tear configuration was analyzed. The grade of tendon retraction was measured according to Patte [21] and the vitality of the muscle (fatty infiltration) was recorded according to the classification of Goutallier [11]. Only cases identified as having stage $3(50-75 \%)$ or 4 (75$100 \%)$ fatty degeneration of the muscle were selected for this study. Furthermore, the size of the RCT was classified according to Bateman [22]. Additionally, during surgery, a specially marked probe was utilized to measure the size of the cuff tear in both the antero-posterior dimension at the 
Table 2 Characteristics of the rotator cuff tears

\begin{tabular}{|c|c|c|c|}
\hline & $\begin{array}{l}\text { Group 1, } \\
\text { partial } \\
\text { repair, } \\
\text { number } \\
(\%)\end{array}$ & $\begin{array}{l}\text { Group } 2, \\
\text { debridement, } \\
\text { number }(\%)\end{array}$ & $\begin{array}{l}\text { All, } \\
\text { number } \\
(\%)\end{array}$ \\
\hline \multicolumn{4}{|l|}{ Size } \\
\hline Large $(3$ to $<5 \mathrm{~cm})$ & $5(23.8)$ & $3(14.3)$ & $8(38.1)$ \\
\hline Massive $(\geq 5 \mathrm{~cm})$ & $16(76.2)$ & $18(85.7)$ & $34(80.1)$ \\
\hline \multicolumn{4}{|l|}{ Location } \\
\hline SSP & $6(28.6)$ & $4(19.1)$ & $10(23.8)$ \\
\hline $\mathrm{SSP}+\mathrm{ISP}$ & $15(71.4)$ & $17(80.1)$ & $32(76.2)$ \\
\hline \multicolumn{4}{|l|}{ Tendon retraction } \\
\hline $\begin{array}{l}\text { Stump between humeral head } \\
\text { and glenoid }\end{array}$ & $5(20.8)$ & $6(25)$ & $11(22.9)$ \\
\hline Stump at level of glenoid & $19(79.2)$ & $18(75)$ & $37(77.1)$ \\
\hline \multicolumn{4}{|l|}{ Fatty infiltration } \\
\hline $50-75 \%$ & $18(85.7)$ & $17(80.1)$ & $35(83.4)$ \\
\hline$>75 \%$ & $3(14.3)$ & $4(19.1)$ & $7(16.6)$ \\
\hline
\end{tabular}

SSP supraspinatus, ISP infraspinatus

Tendon retraction is described by the Patte classification (1990) and muscle vitality (fatty degeneration) is recorded according to the classification of Goutallier (1994)

point of insertion and the medio-lateral dimension. The tear size was recorded as "large" when measuring from 3 to $5 \mathrm{~cm}$ in the two planes and as "massive" when measuring more than $5 \mathrm{~cm}$. The criterion for inclusion in this study were patients with supraspinatus tears alone or in combination with involvement of the infraspinatus tendon. Patients who had a significant subscapularis tear were excluded from this study. The characteristics of the rotator cuff tears are summarized in Table 2.

Postoperatively, the status of the partial rotator cuff repair in group 1 was assessed by sonographic evaluation according to the method of Prickett et al. [23]. Postoperative ultrasound study was done at the second follow-up examination and was performed by the authors, who are experienced with the method. Structural failure of the partial rotator cuff repair was diagnosed when the rotator cuff could not be visualized because of complete retraction under the acromion or when there was a distinct, enlarged focal defect in the rotator cuff with displacement from the surgical insertion.

\section{Clinical assessment}

Subjects were assessed using the Constant score [24] and the DASH score [25]. In addition, range of motion in all directions was assessed by goniometer. Complications were noted. The patients were first examined immediately before surgery, and at $16.8 \pm 3$ and $24.2 \pm 2$ months after surgery. At follow-up, symptoms were assessed by an interview, and all patients were clinically examined by the authors.

\section{Operative technique}

All operations were performed by the authors with the patients in a beach-chair position under general anaesthesia in combination with an interscalene block. Furthermore, we used an articulated hydraulic arm holder (Spider Arm Holder; Tenet Medical Engineering, Calgary, Canada) to hold the arm in various positions. Three routine arthroscopic portals (anterior, lateral, posterior) were used to perform the arthroscopy, and in group 1 additional portals (e.g. antero-lateral) were used to perform the partial rotator cuff repair.

After subtotal removal of the subacromial bursa, debridement of the tear was performed. In group 1 (arthroscopic partial repair) the rotator cuff was tested by grasping the edges of the tendons with an arthroscopic clamp and trying to pull it laterally to the footprint region as much as possible. Then, the cuff was mobilized with traction and blunt dissection as completely as possible. Again, release of adhesions and tendon mobilization was achieved using cautery and full-radius shaver. If necessary, adjacent procedures to mobilize the tendon such as release of the coraco-humeral ligament were performed. Therefore, the rotator cuff lesion was minimized as much as possible according to the anatomy of the tear. In massive tears, convergence sutures were placed first to lateralize the free margin of the tear, and then suture anchors were placed to repair the rotator cuff to the bone by single-row fixation technique. Transfer of the subscapularis tendon was not performed in an case.

In group 2, the torn rotator cuff was debrided and bursectomy was performed. In addition, while maintaining the coracoacromial arch, limited subacromial decompression was done.

Due to biceps tendon pathology (instability, tendinitis, degeneration) in both study groups, biceps tenotomy or tenodesis was always performed (group 1: 16 tenotomies, 4 tenodesis; group 2: 20 tenotomies).

\section{Postoperative rehabilitation}

Postoperative rehabilitation was standardized on an outpatient basis. In group 1, an abduction pillow was worn during the first 4 weeks after surgery. Passive mobilization and assisted active exercises within the pain-free range of motion were also performed up to 6 weeks after surgery. Afterwards, active exercises with and without resistance were initiated. In group 2, patients were mobilized rapidly and a sling was worn only if required during the first 10 days postoperatively. Passive and 
active range-of-motion exercises started the first day after surgery and continued until maximum movement was achieved. All patients were treated with continuous passive motion within the first 3 weeks. Additionally, for all patients, physical therapy was supplemented in our institution's outpatient rehabilitation unit for about 6 months to strengthen the shoulder and maximize the range of motion until there was maximum improvement.

\section{Statistical analysis}

We used analysis of variance for repeated measures to detect possible differences between the two treatment groups during follow-up, and post hoc least significant difference (LSD) test where appropriate. The intra-subject factor was time (preoperative, and 16 and 24 months after surgery) and the inter-subject factor was status (partial repair, debridement). We used the parametric paired $t$ test to compare preoperative values within the treatment groups. A significance level less than 0.05 was adopted. We used SPSS statistical software, version 15.0 for Windows, for all calculations. Unless otherwise specified, results are given as mean \pm standard deviation.

\section{Results}

Clinical assessment

There were no significant differences between the groups with regard to age $(P=0.056, F=3.723)$, gender $(P=0.733, \quad F=0.471)$ or follow-up (follow-up 1: $P=0.146, F=0.092$; follow-up 2: $P=0.128, F=0.385)$.

The pre- and postoperative functional status (Constant score, DASH score and range of motion) of the patients are presented in Tables 3 and 4. Except for internal rotation $(P=0.008, \quad F=5.732) \quad$ and strength $\quad(P=0.009$, $F=0.182$ ) the preoperative values for active range of motion, Constant score and DASH score did not differ significantly between the treatment groups.

The mean operative time in group 1 was $89 \pm 29 \mathrm{~min}$, which was statistically different from the value of $65 \pm 26 \mathrm{~min}$ in group $2(P=0.008, F=0.015)$.

There was a main effect of time on active range of motion $(P<0.01)$, Constant score $(P<0.01, F=161.25)$ and DASH score $(P<0.01, F=235.24)$, which would suggest that postoperative results in both groups demonstrated highly significant improvement compared with
Table 3 Preoperative and postoperative values of range of movement in the entire series (group 1, partial rotator cuff repair; group 2, debridement)

Data are given as mean \pm standard deviation

\begin{tabular}{|c|c|c|c|c|c|}
\hline & Preoperative & Follow-up 1 & Follow-up 2 & $P$ value & $F$ value \\
\hline \multicolumn{6}{|c|}{ Abduction $\left(^{\circ}\right)$} \\
\hline Group 1 & $97.7 \pm 37.7$ & $151.2 \pm 20.8$ & $144.0 \pm 17.8$ & \multirow[t]{3}{*}{$<0.01$} & \multirow[t]{3}{*}{13.249} \\
\hline Group 2 & $93.5 \pm 38.9$ & $123 \pm 32.7$ & $103.5 \pm 20.3$ & & \\
\hline All & $96.3 \pm 37.7$ & $137.9 \pm 30.2$ & $125 \pm 27.8$ & & \\
\hline \multicolumn{6}{|c|}{ Adduction $\left(^{\circ}\right)$} \\
\hline Group 1 & $28 \pm 10.4$ & $38.7 \pm 3.9$ & $37.2 \pm 4.9$ & \multirow[t]{3}{*}{0.712} & \multirow[t]{3}{*}{0.341} \\
\hline Group 2 & $28 \pm 9.5$ & $36.7 \pm 6.1$ & $35.2 \pm 6.3$ & & \\
\hline All & $27.5 \pm 9.9$ & $37.4 \pm 5.7$ & $35.9 \pm 6.1$ & & \\
\hline \multicolumn{6}{|c|}{ Anteversion $\left(^{\circ}\right)$} \\
\hline Group 1 & $105.3 \pm 39.1$ & $162 \pm 25.2$ & $145.2 \pm 28.1$ & \multirow[t]{3}{*}{0.173} & \multirow[t]{3}{*}{1.798} \\
\hline Group 2 & $98.5 \pm 39.5$ & $136 \pm 28.3$ & $126.2 \pm 28.8$ & & \\
\hline All & $102.7 \pm 39.2$ & $150 \pm 29.2$ & $136.6 \pm 29.5$ & & \\
\hline \multicolumn{6}{|c|}{ Retroversion $\left({ }^{\circ}\right)$} \\
\hline Group 1 & $29.7 \pm 10.7$ & $37.0 \pm 8$ & $34.5 \pm 8.8$ & \multirow[t]{3}{*}{0.603} & \multirow[t]{3}{*}{0.509} \\
\hline Group 2 & $34.5 \pm 8.4$ & $39 \pm 3.1$ & $37 \pm 5.7$ & & \\
\hline All & $31.7 \pm 9.7$ & $38 \pm 6$ & $35.7 \pm 7.4$ & & \\
\hline \multicolumn{6}{|c|}{ Internal rotation $\left(^{\circ}\right)$} \\
\hline Group 1 & $67.5 \pm 15.5$ & $79.5 \pm 12.7$ & $79.0 \pm 12.5$ & \multirow[t]{3}{*}{0.79} & \multirow[t]{3}{*}{0.262} \\
\hline Group 2 & $49.5 \pm 26$ & $72.7 \pm 16.5$ & $71.6 \pm 15.6$ & & \\
\hline All & $58.6 \pm 23.0$ & $76.1 \pm 14.9$ & $75.4 \pm 14.5$ & & \\
\hline \multicolumn{6}{|c|}{ External rotation $\left({ }^{\circ}\right)$} \\
\hline Group 1 & $41.7 \pm 23.7$ & $47 \pm 12.1$ & $45 \pm 10.6$ & \multirow[t]{3}{*}{0.955} & \multirow[t]{3}{*}{0.046} \\
\hline Group 2 & $40.5 \pm 23.5$ & $46.5 \pm 19.8$ & $42.7 \pm 18.0$ & & \\
\hline All & $41.1 \pm 23.3$ & $46.7 \pm 16.2$ & $43.8 \pm 14.6$ & & \\
\hline
\end{tabular}


Table 4 Preoperative and postoperative values of Constant score and DASH score in the entire series (group 1, partial rotator cuff repair; group 2, debridement)

\begin{tabular}{|c|c|c|c|c|c|}
\hline & Preoperative & Follow-up 1 & Follow-up 2 & $\begin{array}{l}P \\
\text { value }\end{array}$ & $\begin{array}{l}F \\
\text { value }\end{array}$ \\
\hline \multicolumn{6}{|c|}{ Pain (points) } \\
\hline Group 1 & $2.5 \pm 2.5$ & $9.5 \pm 5.6$ & $9 \pm 5.2$ & \multirow[t]{3}{*}{0.172} & \multirow[t]{3}{*}{1.802} \\
\hline Group 2 & $2.3 \pm 2.5$ & $8 \pm 5.4$ & $6.3 \pm 3.9$ & & \\
\hline All & $2.4 \pm 2.5$ & $8.7 \pm 5.5$ & $7.6 \pm 4.8$ & & \\
\hline \multicolumn{6}{|c|}{ Activity (points) } \\
\hline Group 1 & $7 \pm 1.9$ & $15.9 \pm 2.3$ & $14.9 \pm 2.2$ & \multirow[t]{3}{*}{$<0.01$} & \multirow[t]{3}{*}{21.391} \\
\hline Group 2 & $6.5 \pm 2.4$ & $12 \pm 3.8$ & $10.1 \pm 2.8$ & & \\
\hline All & $6.8 \pm 2.2$ & $13.9 \pm 3.7$ & $12.5 \pm 3.5$ & & \\
\hline \multicolumn{6}{|c|}{ Motion (points) } \\
\hline Group 1 & $20.5 \pm 5.3$ & $28.9 \pm 5$ & $27.3 \pm 4.2$ & \multirow[t]{3}{*}{0.009} & \multirow[t]{3}{*}{4.967} \\
\hline Group 2 & $17.7 \pm 6.7$ & $23.9 \pm 6$ & $20.6 \pm 6$ & & \\
\hline All & $19.1 \pm 6.1$ & $26.4 \pm 6$ & $23.9 \pm 6.1$ & & \\
\hline \multicolumn{6}{|c|}{ Strength (points) } \\
\hline Group 1 & $6.9 \pm 4.1$ & $9.4 \pm 4.8$ & $7 \pm 3.8$ & \multirow[t]{3}{*}{0.645} & \multirow[t]{3}{*}{0.440} \\
\hline Group 2 & $3.4 \pm 3.7$ & $5.6 \pm 5.4$ & $3.8 \pm 3.7$ & & \\
\hline All & $5.1 \pm 4.2$ & $7.5 \pm 5.4$ & $5.4 \pm 4$ & & \\
\hline \multicolumn{6}{|c|}{ Total (points) } \\
\hline Group 1 & $36.9 \pm 7$ & $63.7 \pm 13.2$ & $58.2 \pm 11$ & \multirow[t]{3}{*}{$<0.01$} & \multirow[t]{3}{*}{8.561} \\
\hline Group 2 & $29.9 \pm 11.2$ & $49.6 \pm 16.4$ & $40.7 \pm 12.4$ & & \\
\hline All & $33.4 \pm 9.8$ & $56.6 \pm 16.3$ & $49.5 \pm 14.6$ & & \\
\hline \multicolumn{6}{|c|}{ Total adjusted (points) } \\
\hline Group 1 & $45.9 \pm 9.2$ & $79.4 \pm 17.5$ & $72.8 \pm 16$ & \multirow[t]{3}{*}{$<0.01$} & \multirow[t]{3}{*}{8.702} \\
\hline Group 2 & $37 \pm 13.6$ & $61.3 \pm 19.9$ & $50.4 \pm 15.3$ & & \\
\hline All & $41.5 \pm 12.3$ & $70.4 \pm 20.6$ & $61.5 \pm 19.2$ & & \\
\hline \multicolumn{6}{|c|}{ DASH score (points) } \\
\hline Group 1 & $64.6 \pm 11.9$ & $16 \pm 16.1$ & $23.8 \pm 16.8$ & \multirow[t]{3}{*}{0.119} & \multirow[t]{3}{*}{2.185} \\
\hline Group 2 & $69.5 \pm 10.5$ & $29.7 \pm 19.7$ & $35.3 \pm 18.6$ & & \\
\hline All & $67.1 \pm 11.4$ & $22.9 \pm 19.1$ & $29.6 \pm 18.4$ & & \\
\hline
\end{tabular}

Data are given as mean \pm standard deviation

preoperative values in terms of most parameters (except active external rotation; $P=0.157, F=0.1899$ ).

We found a significant interaction between status and time during follow-up for abduction (Table 3). This indicates that this parameter shows different behaviour between the two groups. Post hoc analysis of the values for abduction demonstrate, in the debridement group, that after an initial increase assessed by the first follow-up evaluation $(P<0.01)$ the second postoperative values did not differ significantly $(P=0.074)$ from the preoperative values. In contrast, the improvement of abduction after surgery in the partial repair group was detectable during the entire followup.

The postoperative values for adduction, anteversion, retroversion, and internal and external rotation did not show significant differences between the two groups. This indicates that the increase in range of motion in these parameters after surgery in patients treated by partial rotator cuff repair and arthroscopic debridement was comparable.

Furthermore, a significant interaction between time and status was found for both the Constant score and the ageand gender-related Constant score, which would suggest that patients treated with partial repair showed better clinical outcome during follow-up (Table 4). This result is related to greater improvement in the categories of activity and motion after the first examination $(P<0.01$, $F=5.553 ; P=0.008, F=0.187)$ as well as after the final examination $(P<0.01, F=2.659 ; P=<0.01$, $F=4.682$ ). Regarding pain, we found a significant improvement after surgery in the entire series but no differences between the treatment groups. Likewise strength showed a postoperative increase in the entire series, but postoperative values did not reach statistical significance between the two groups.

The DASH score demonstrated a significant improvement compared with preoperative measurements, but we could not detect a significant difference between the two treatment groups during follow-up $(P=0.948$, $F=0.004)$.

\section{Postoperative rotator cuff evaluation}

Structural failure of partial rotator cuff repair was detected by sonographic evaluation in 11 of the 21 patients in group 1. The remaining ten patients had no radiological signs of renewed increase of the residual defect after incomplete repair, but a very thin cuff.

Complications and reoperations

One patient in group 2 developed 20 months after surgery, severe glenohumeral arthritis, and therefore shoulder hemiarthroplasty was performed.

One patient in group 1 had a reoperation (17 months after initial surgery) due to persistent postoperative pain and was treated by arthroscopic excision of hypertrophic bursal scar tissue and revision acromioplasty.

\section{Discussion}

This study compares early and mid-term results of arthroscopic partial repair and arthroscopic debridement in patients with massive RCT with stage 3 or 4 fatty degeneration. In general, our findings showed that both surgical treatment options in combination with tenotomy/tenodesis of the biceps led to significant decrease in pain and improvement of shoulder function. Furthermore, the 
clinical outcome results after the two different surgical procedures during follow-up are comparable to those of other investigations $[16,17,19,26]$.

The major finding of our study was that patients treated with partial rotator cuff repair seemed to have greater improvement of shoulder function compared with patients treated with arthroscopic debridement alone. Overall, the activities of daily living after partial repair, especially in the early and mid-term period after surgery, were superior in comparison with after arthroscopic debridement. These findings were consistent with the study of Duralde et al. [26], who found that the results of partial repair were also superior to those of debridement. Likewise, Burkhart et al. [15] showed that partial repair of large and massive RCT leads to significant pain relief and improvement of shoulder function.

Both of these studies and our own results support the assumption that partial repair of massive RCT attempts to improve the biomechanics of the shoulder. The concept of partial repair in terms of a "margin convergence technique" to restore the shoulder's essential force couples is due to Burkhart et al. [16], according to which the RCT is converted to a "functional tear". In this theory, the rebalanced force couple of the remaining anterior and posterior parts of the rotator cuff recover shoulder stability, which subsequently allows better function and decreased pain.

Another result of the present study was the relatively high rate of structural failures of the partial rotator cuff repair of about $52 \%$, evaluated during the final examination by ultrasound.

Although MRI has been accepted as the most useful examination method [27], we used ultrasound due to its advantages of cost effectiveness, time efficiency and noninvasive nature. Furthermore, the accuracy of ultrasound examination in previously operated shoulders was investigated in a recent study of Prickett et al. [23], who showed sensitivity of $91 \%$ and specificity of $86 \%$ for detection of $\mathrm{RCT}$, generally comparable to those of MRI investigations [27]. However, the rate of recurrent tears in the present study was comparable to in other studies that investigated the failure rates of rotator cuff repairs of large and massive defects $[28,29]$. Despite the high rate of structural failures, the patients in the partial repair group demonstrated greater and longer improvement of shoulder function than the patients treated with debridement alone, at least during our follow-up.

In our opinion it is rather unlikely that this is related to differences in postoperative rehabilitation between the groups. Except for the initial temporary immobilization and passive mobilization in group 1 , the subsequent longterm rehabilitation program was comparable in both patient groups.

Therefore, our results and the fact that also patients regain function after a "simple" debridement of the RCT points towards the problem that the underlying mechanisms of shoulder function improvement in those patients have not yet been fully understood. It has been suggested that decreased pain and improved function despite radiographic evidence of failed rotator cuff repair may be the result of complete or partial decompression of a tethered suprascapular nerve $[30,31]$. Another possible explanation is reduction of pain-related muscle activity inhibition via arthroscopic debridement, lavage and intra-articular synovectomy, leading to increased shoulder muscle strength. This assumption is supported by the findings of Itoi et al. [32] that a pain block produced significant increase in strength of abduction in full RCT.

Again, the superior functional outcome in the partial repair group may be explained by the "margin convergence theory" and/or the release of the suprascapular nerve. In structural failures of rotator cuff repair it can be speculated that the dimension of the re-tear was smaller than the preoperative defect size. Presumably, the tear size in the debridement group increased too with time, resulting in more progressive instability and decentration of the glenohumeral joint than in the partial repair group. This may be a possible explanation for the finding of greater improvement of shoulder function even with radiographic evidence of failed partial rotator cuff repair.

When performing partial repair in an open procedure, approach-related weakening of the deltoid muscle has to be considered [33, 34]. This may affect the functional outcome of further surgical procedures such as shoulder arthroplasty. In this regard, the potential advantage of arthroscopic rotator cuff repair in terms of reduced deltoid morbidity has to be considered. Nevertheless, recent studies comparing mini-open with all-arthroscopic repair for small and medium-sized RCT have shown that the functional outcomes of both methods are nearly equivalent [35, 36]. Although speculative, in large and massive RCT with a probably high rate of re-tears, it is to be expected that the potential benefit of all-arthroscopic repair is even greater due to less deltoid weakening.

The advantages of arthroscopic subacromial decompression and rotator cuff debridement include an accelerated rehabilitation program and the reported lower complication rates of this less invasive procedure [18]. Furthermore, most of the patients in the debridement group were operated on an outpatient basis, whereas patients in the partial repair group stayed in hospital for at least 3 days after surgery. There exists some strong evidence that the satisfactory results with debridement deteriorate during long-term follow-up [18]. For instance, Zvijac et al. [37] found a significant decrease in pain assessment and shoulder function after 3- to 6-year follow-up in patients treated with arthroscopic subacromial decompression for irreparable RCT. 
In addition, the results of the present study point toward faster deterioration of postoperative shoulder function improvement in the debridement group. However, despite uncertain long-term results, we see an indication for arthroscopic debridement in particular in elderly patients with low functional demands and/or inability to undergo longer rehabilitation after surgery. A further aspect in favour of arthroscopic debridement to bear in mind is that temporary immobilization of the shoulder as after partial rotator cuff repair and the associated interruption of active physical therapy are avoided. Therefore, the potential risk for development of a secondary frozen shoulder is potentially smaller, even though in the present study we could not detect an increased occurrence of shoulder stiffness in the partial repair group.

A limitation of the present study is the potential bias in randomization with regard to the two treatment strategies. We cannot exclude that patients in the partial repair group were more motivated to complete extensive rehabilitation after surgery, resulting in better functional outcome. We tried to minimize this influencing factor with a specially designed, almost comparable long-term rehabilitation program after surgery for both groups.

In conclusion, all patients in our series had good or satisfactory outcome after rotator cuff surgery. The present study indicates that, in cases of massive RCT, early and mid-term results of partial repair were slightly superior to those of arthroscopic debridement alone, indicating a preference for the former procedure.

Acknowledgments This research was supported by Deutsche Arthrose Hilfe e.V.

Conflicts of interest None.

\section{References}

1. Norwood LA, Barrack R, Jacobson KE (1989) Clinical presentation of complete tears of the rotator cuff. J Bone Joint Surg Am 71:499-505

2. Murrell GA, Walton JR (2001) Diagnosis of rotator cuff tears. Lancet 357:769-770

3. Ainsworth R, Lewis JS (2007) Exercise therapy for the conservative management of full thickness tears of the rotator cuff: a systematic review. Br J Sports Med 41:200-210

4. Alvarez CM, Litchfield R, Jackowski D et al (2005) A prospective, double-blind, randomized clinical trial comparing subacromial injection of betamethasone and xylocaine to xylocaine alone in chronic rotator cuff tendinosis. Am J Sports Med 33:255-262

5. Wolf BR, Dunn WR, Wright RW (2007) Indications for repair of full-thickness rotator cuff tears. Am J Sports Med 35:1007-1016

6. Gohlke F, Rolf O, Bohm D (2007) Open reconstruction of the rotator cuff. Orthopade 36:834-847

7. Habermeyer P, Lehmann L, Lichtenberg S (2000) Rotator cuff tears: diagnosis and therapy. Orthopade 29:196-208
8. Dietz SO, Habermeyer P, Magosch P (2002) Current concepts in treatment of rotator cuff tears. Zentralbl Chir 127:194-202

9. Loew M (2000) Traumatic development of rotator cuff lesion. Scientific principles and consequences for expert assessment. Orthopade 29:881-887

10. DeFranco MJ, Bershadsky B, Ciccone J et al (2007) Functional outcome of arthroscopic rotator cuff repairs: a correlation of anatomic and clinical results. J Shoulder Elbow Surg 16:759-765

11. Goutallier D, Postel JM, Bernageau J et al (1994) Fatty muscle degeneration in cuff ruptures. Pre- and postoperative evaluation by CT scan. Clin Orthop Relat Res 78-83

12. Matthews TJ, Hand GC, Rees JL et al (2006) Pathology of the torn rotator cuff tendon. Reduction in potential for repair as tear size increases. J Bone Joint Surg Br 88:489-495

13. Galatz LM, Griggs S, Cameron BD, Iannotti JP (2001) Prospective longitudinal analysis of postoperative shoulder function: a ten-year follow-up study of full-thickness rotator cuff tears. J Bone Joint Surg Am 83-A:1052-1056

14. Gerber C, Fuchs B, Hodler J (2000) The results of repair of massive tears of the rotator cuff. J Bone Joint Surg Am 82:505515

15. Burkhart SS (2001) Arthroscopic treatment of massive rotator cuff tears. Clin Orthop Relat Res 107-18

16. Burkhart SS, Nottage WM, Ogilvie-Harris DJ et al (1994) Partial repair of irreparable rotator cuff tears. Arthroscopy 10:363-370

17. Ogilvie-Harris DJ, Demaziere A (1993) Arthroscopic debridement versus open repair for rotator cuff tears. A prospective cohort study. J Bone Joint Surg Br 75:416-420

18. Melillo AS, Savoie FH III, Field LD (1997) Massive rotator cuff tears: debridement versus repair. Orthop Clin North Am 28:117124

19. Gartsman GM (1997) Massive, irreparable tears of the rotator cuff. Results of operative debridement and subacromial decompression. J Bone Joint Surg Am 79:715-721

20. Moser M, Jablonski MV, Horodyski M, Wright TW (2007) Functional outcome of surgically treated massive rotator cuff tears: a comparison of complete repair, partial repair, and debridement. Orthopedics 30:479-482

21. Patte D (1990) Classification of Rotator Cuff Lesions. Clin Orthop Relat Res 81-86

22. Bateman JE (1963) The diagnosis and treatment of ruptures of the rotator cuff. Surg Clin North Am 43:1523-1530

23. Prickett WD, Teefey SA, Galatz LM et al (2003) Accuracy of ultrasound imaging of the rotator cuff in shoulders that are painful postoperatively. J Bone Joint Surg Am 85-A:1084-1089

24. Constant CR, Murley AH (1987) A clinical method of functional assessment of the shoulder. Clin Orthop Relat Res 160-4

25. Hudak PL, Amadio PC, Bombardier C (1996) Development of an upper extremity outcome measure: the DASH (disabilities of the arm, shoulder and hand) [corrected]. The Upper Extremity Collaborative Group (UECG). Am J Ind Med 29:602-608

26. Duralde XA, Bair B (2005) Massive rotator cuff tears: the result of partial rotator cuff repair. J Shoulder Elbow Surg 14:121-127

27. de Jesus JO, Parker L, Frangos AJ, Nazarian LN (2009) Accuracy of MRI, MR arthrography, and ultrasound in the diagnosis of rotator cuff tears: a meta-analysis. AJR Am J Roentgenol 192:1701-1707

28. Verma NN, Dunn W, Adler RS et al (2006) All-arthroscopic versus mini-open rotator cuff repair: a retrospective review with minimum 2-year follow-up. Arthroscopy 22:587-594

29. Sugaya H, Maeda K, Matsuki K, Moriishi J (2007) Repair integrity and functional outcome after arthroscopic double-row rotator cuff repair. A prospective outcome study. J Bone Joint Surg Am 89:953-960

30. Costouros JG, Porramatikul M, Lie DT, Warner JJ (2007) Reversal of suprascapular neuropathy following arthroscopic 
repair of massive supraspinatus and infraspinatus rotator cuff tears. Arthroscopy 23:1152-1161

31. Mallon WJ, Wilson RJ, Basamania CJ (2006) The association of suprascapular neuropathy with massive rotator cuff tears: a preliminary report. J Shoulder Elbow Surg 15:395-398

32. Itoi E, Minagawa H, Sato T et al (1997) Isokinetic strength after tears of the supraspinatus tendon. J Bone Joint Surg Br 79:77-82

33. Hata Y, Saitoh S, Murakami N et al (2004) Atrophy of the deltoid muscle following rotator cuff surgery. J Bone Joint Surg Am 86A:1414-1419

34. Gumina S, Di GG, Perugia D, Postacchini F (2008) Deltoid detachment consequent to open surgical repair of massive rotator cuff tears. Int Orthop 32:81-84
35. Pearsall AW, Ibrahim KA, Madanagopal SG (2007) The results of arthroscopic versus mini-open repair for rotator cuff tears at mid-term follow-up. J Orthop Surg Res 2:24

36. Kang L, Henn RF, Tashjian RZ, Green A (2007) Early outcome of arthroscopic rotator cuff repair: a matched comparison with mini-open rotator cuff repair. Arthroscopy 23:573-582

37. Zvijac JE, Levy HJ, Lemak LJ (1994) Arthroscopic subacromial decompression in the treatment of full thickness rotator cuff tears: a 3- to 6-year follow-up. Arthroscopy 10:518-523 